\title{
Malignant Peritoneal Neoplasm
}

National Cancer Institute

\section{Source}

National Cancer Institute. Malignant Peritoneal Neoplasm. NCI Thesaurus. Code C3538.

A primary or metastatic malignant neoplasm involving the peritoneum. Representative examples include carcinoma and malignant mesothelioma. 